\title{
The Effect of the Kahoot Quiz on the Student's Results in the Exam
}

\author{
Áron Tóth" ${ }^{*}$, Péter Lógó1, Emma Lógó1 \\ ${ }^{1}$ Department of Ergonomics and Psychology, Faculty of Economic and Social Sciences, Budapest University of Technology and \\ Economics, H-1111 Budapest, P.O.B. 91, Hungary \\ ${ }^{*}$ Corresponding author, e-mail: totharon@erg.bme.hu
}

Received: 26 April 2018, Accepted: 22 May 2018, Published online: 28 January 2019

\begin{abstract}
Students taking low-stake quizzes in a gamified environment shows improvement on their studies, thus has the potential to be an effective part in an improved learning experience. Previous researches show that implementing gamification into the educational system has positive outcome on the student's engagement, motivation and the overall experience of learning. In this study is a field experiment, where quizzes were created with the Kahoot application, to bring action and visual triggers into the classroom. The aim of this paper to measure the long-term learning effect of the Kahoot quiz in the exams. Several of the quiz questions during the class were purposefully blended into the exam's question bank as a multiple choice or a true or false question. In this research 200 bachelor students participated in a 14-week long elective course. The data was collected weekly from the Kahoot quizzes and from the two mandatory exams. All the results from the Kahoot quiz and the exams provided the base of the analysis. Furthermore, the exam results were analyzed based on number of Kahoot quizzes they took part, a comparison of the results of each question based. The results show that students who took part in more Kahoot quizzes tend to reach higher exam mark. Moreover, they marked more correct answers and less incorrect ones. As a conclusion, using some level of game-based learning has a positive effect on the student's results and perception of learning.
\end{abstract}

Keywords

Kahoot, gamification, quiz, exam, education

\section{Introduction}

In the present, the educational system still uses a traditional framework for teaching. This is in great contrast to the outside world where everything is digital, with lot of visual impact and quick updates to engage people towards regular use of an app, becoming a loyal customer or engaging in sporting activities. In recent years, a new trend called gamification has evolved as an approach to engage and encourage active participation (Bista et al., 2012). By definition, gamification is the use of game elements in a non-game context (Deterding et al., 2011). It is important to separate play, which is a free form of action, and games to entertain from serious games that usually encompass real-world activities (Barata et al., 2015).

Due to the novelty of the concept of gamification (Hamari et al., 2014), several frameworks and concepts have been introduced. The most well accepted is Octalysis, which builds up on eight core drives (Chou, 2015). Another well-known one is the MDA framework, which attempts to bridge the gap between game design and development, game criticism, and technical game research (Hunicke et al., 2004). On the side of understanding the players in more depth, Andrzej created the Hexad Player Type, where each player type is matched with their motivational game element (Andrzej, 2015).

Gamification means utilizing the motivational and emotional power of games for other purposes not solely related to the entertaining purposes of the game itself (Sailer et al., 2013). One purpose could be to engage and boost student activity during a lecture or even to create a positive change in attitudes towards studying and taking exams.

This article presents an experiment where the students were asked the same questions in the Kahoot quiz and their exams. In Section 2, theories connected to gamification and practices, including related work, are introduced. Section 3 summarizes the assessment tool. Section 4 lays out the research details, context and participants and the 
experiment process. Section 5 presents the results from the experiment. Section 6 concludes the article.

\section{Gamification in education}

Gamification as a concept has been implemented into various fields (Tóth and Tóvölgyi, 2017). Its success in different industries suggests that it could also be used in education to increase student engagement and drive learning behavior (Chapman and Rich, 2017). There are discussions on the different approaches to the term associated with education and gamification, like Game Based Learning (GBL) or serious games, and, according to Oliver (2017), there are two education gamification types: structural and content.

Based on prior experiences, the success of gamification in education lies on several pillars. The first influencing factor is the depth and the complexity of the adaptation of game design elements. The second factor can be summarized as the learning styles. The third is the player or, in this case, the students' motivational response to the various game elements. The last effect focuses on the possibilities of a gamified learning environment in practice.

\subsection{Levels of applying gamification in education}

The adaptation of gamification in education can happen in various levels, based on the depth of applying game design elements, theories, etc.

In the basic level (1), only a gamified application is used to boost student activity; however, the course follows the traditional teaching concept. Such applications are generally Interactive Response Systems (IRS), such as Kahoot, Socrative and Plickers (Solmaz and Cetin, 2017). More detail on these IRSs can be found in Section 3. Even at this low level, studies indicate that IRSs can heighten students' interest in the lesson and encourage students to become more ambitious for success (Bicen and Kocakoyun, 2018). The downside is that the positive effects, such as engagement, are only present when the gamified application is in use.

The next level (2) would be when game design elements are added to the course to reward certain actions. There are a wide variety of elements to choose from to promote behavior change. There are few popular components, such as points, shields and leaderboards, commonly named PBLs (Points, Badges \& Leaderboards achievement) (González et al., 2016). At this level, a comprehensive understanding of the behavior is missing, which could result in negative effects (Palmer et al., 2012).

In the third level (3), game design elements are added based on a detailed understanding of the placements of elements. This is to reach a better result when applying gamification. They provide processes and factors to be considered to create meaningful gamification.

One of the most known processes is the Hook Model (Eyal, 2014), which characterizes the four phases of a typical habit-forming product: Trigger phase, Action phase, Reward phase and Investment phase (Liu and Li, 2016).

Secondly, the Fogg's Behavior Model is one that identifies and defines three factors that control whether a behavior is performed (Fogg, 2009). For a behavior to occur, the motivation, ability and trigger must converge at the same moment when reaching the activation threshold (Challco et al., 2015).

Furthermore, the Self-Determination Theory (SDT) (Ryan and Deci, 2000) describes things humans find intrinsically motivating, relying on just three core ideas: autonomy, competence, and relatedness (Lewis, 2014).

Lastly, a sub-theory of SDT comes out of the field of Education Organismic Integration Theory (Nicholson, 2012). It states that when people act upon internalized motivations, they will have a more positive outlook toward the activity than if they are doing something due to extrinsic motivation (Reiners and Wood, 2015). This theory suggests that meaningful game elements are intrinsically motivating regardless of any external rewards that may be associated with them (Seaborn and Fels, 2015).

The fourth level (4) is when the gamified system is prepared based on the phases of the user journey (Chou, 2015). In Level 2, the four phases of Octalysis are differentiated into: Discovery, Onboarding, Scaffolding and Endgame. This is why the game experience usually evolves during the player journey, adapting itself to the variation of the player's skills and emotions (Rapp, 2014). Therefore, the game varies in a way that the given game task is dynamically balanced with individual skill levels, as it is described by Csikszentmihályi in Flow Theory (Sharek and Wiebe, 2014).

The highest, most complex level (5) takes into consideration the different student types and the different learning styles. The students' typology can be viewed from the game side as player types. Importantly, to avoid clouding the potential positive effects of gamification, gamified learning environments must be designed correctly, and learners' individual differences and motivations must be taken into consideration (Kocadere and Çağlar, 2018).

\subsection{Perspectives for further research: Learning styles and user types}

Studies agree that it can be a meaningful way to increase student motivation and improve educational effectiveness 
(Bernik et al., 2017). Gamified learning environments have been applied from elementary education (Simões et al., 2013) to university level (Hamari, 2017), but when applying gamification, it is important to understand different learning styles. Felderman and Silverman (Chen and Lin, 2014) proposed an Index of Learning Styles (ILS) for identifying learners in four learning styles, namely active/reflective, sensitive/intuitive, visual/verbal and sequential/global. The Learning Style Inventory (LSI) is a model created by Kolb, where learning styles are based on a four-stage learning cycle consisting of: Concrete Experience (CE), Reflective Observation (RO), Abstract Conceptualization (AC) and Active Experimentation (AE) (Lindberg and Laine, 2017). The model was then adopted by Honey and Mumford (1982) in their proposal of a typology of learners that distinctively describes the learning styles in each stage (Bishop, 2014). Magoulas et al. (2003) introduced a complex learning system called INSPIRE, that unifies several processes, such as developing the educational material, assessing the learner's knowledge level and exploiting individual traits (e.g. the student's dominant learning style), planning the lesson content, delivery and presentation and providing the appropriate navigation support to the learner (Magoulas et al., 2003).

A gamified environment builds up from game design elements based on the preferred outcome. The e-learning user interfaces and choice of game elements and game mechanics in relation to more personal attributes, such as that of personality types and traits (Hercegfi, 2011), of an individual may assist the user in utilizing elements that we believe are intrinsically motivating to the player, rather than external rewards and objectives (Ferro et al., 2013). A large number of previous studies were published investigating the effectiveness of motivating different types of users with different game design elements. If different game elements activate different motivators in different types of users then this could be adapted for education as well.

Scholars such as Bartle, Caillois and Fullerton identify player typologies of games and the characteristics that players exhibit (such as competitiveness, sociability and exploratory behaviors) within games (Ferro et al., 2013). Bartle (1996) separates four player types: achievers, explorers, socialisers and killers, based on the axes of acting-interacting and players-world. Fullerton's category is based on pleasures of play from the point of view of the player. The foundation of Andrzej's Hexad User Type model is rooted in theories on intrinsic and extrinsic motivation (Diamond et al., 2015). Each of the six user type's motivations is activated by different gamification elements.
Studies have also been carried out to understand more about the student categorization; however, there is a lack of studies exploring the effect of gamified elements in a learning environment. There are some results showing that player types are somewhat in correlation with the students' actions (Conole et al., 2015). In other studies, the students were categorized and analyzed based on their participation patterns (Taylor, 2000). Furthermore, another study focused on the students' participation, and the results showed some connection between gaming habits based on the BrainHex classification (Barata et al., 2014).

\subsection{The gamified learning environments}

In recent years, gamified learning environments have spread to fulfill the needs of both teachers and students from the most basic level to the complex level. Furthermore, applications and platforms with different visual representations and eased usability parameters meet with the needs of K-6 (e.g. ClassDojo, Socrative, Schoooools.com) all the way up to higher education (e.g. Classflow, Google School) (Simões et al., 2013).

Applying gamification in higher education can be effective where a digital learning management system (LMS) is in use, for example, Moodle or BlackBoard (Bernik et al., 2017). Students can access different study materials, communicate with each other and teachers and individually and constantly test their knowledge online. Teachers can prepare course materials and setup reviews, grade and also monitor students' activities (Dečman, 2015). A reason behind the popularity of Moodle could be that new features and modifications can be implemented at a minimal cost. On the other hand, the lack of dedicated support could be a drawback (Machado and Tao, 2007).

From the gamification point of view, both systems have the possibility to implement basic (e.g. PBL, Avatar, Progress Bar) and somewhat advanced (e.g. levels) and personalized game design elements.

After discussing the theories and possibilities of gamification in education, the practical application will be introduced.

\section{In practice}

The study focuses on measuring the effectiveness of several low-stakes quizzes in the results of exams.

\subsection{Student-Response Systems}

During recent years, as technology has developed, student response systems have been created, which teachers 
have continually experimented with. The first generation of Student Response Systems (SRS) were based on special hardware that allowed students to give their answers using clickers, keypads, handsets or zappers (Wang et al., 2016). As smartphones and laptops became common, these systems changed. The benefit of these quiz systems is that no special equipment is needed, only devices that everyone carries.

Studies show that gamified quiz applications (e.g. Socrative, Kahoot, Quizlet Live, Mentimeter, Poll Everywhere or Plickers) are welcomed by students. Students became interested in using different technologies, such as the QR code cards, and liked the colorful interfaces. This significantly affected the immediate feedback in answers given to the open-ended questions (Solmaz and Cetin, 2017). The above-mentioned applications provide several types of question-answer options, quizzes and short answers to choose from. Most of these utilize points, leaderboards and fast feedback from the game element pool.

Kahoot is a game-based SRS (GSRS) that was introduced to the public in the fall of 2013. The main difference between a GSRS and a SRS is that the game-based version focuses more on engaging and motivating the students (Wang et al., 2016). Kahoot is educational software that has the potential to prepare online questionnaires, discussions or exams, as well as to enable students to cooperate in terms of research topics (Bicen and Kocakoyun, 2018).

Previous studies report an improvement in performance if regular, quick quizzes had been used previously. Low-stakes quizzes have shown improved summative exam scores over the course of a semester relative to not being quizzed (Iwamoto et al., 2017). In other studies, using Kahoot improved student motivation (Bicen and Kocakoyun, 2018) (Tan et al., 2018). Students using game-based student response systems compared with paper forms or simple non-game-based student response systems were more engaged, motivated and focused and enjoyed it more (Wang et al., 2016).

\section{Methods and procedures}

In the research, 200 bachelor students participated in a 14-week long elective university course, which followed an experimental gamified framework (see more: Toth and Logo, 2017). During the semester, all the classes ended with a Kahoot quiz. Participation in the quiz was not mandatory; however, the correct answers were rewarded with extra points. Each quiz contained five multiple choice questions based on the given lecture topic. Data was collected on attendance weekly, and feedback was given to the teacher on how well the students understood the lecture. After each lecture, the points collected in the quiz were transferred to the Moodle course page. To complete the course, students had to pass two exams. To measure the effectiveness of the Kahoot quizzes, several questions were asked in the exams.

In the research, from a total of eight Kahoot quizzes, 17 question results were measured. The reasons for this were that not all quiz questions were suitable for the exam format, and the first quiz was part of the onboarding phase to familiarize the students with the Kahoot quiz process; therefore, those questions were not used in the exam.

\subsection{Purpose of the study}

The purpose of this research is to find out how effective the Kahoot quiz was in the learning process of those students who took part and how well they recalled the information during the exam, considering that they had already answered some of the questions during the semester.

\subsection{Research design}

The students in the class were divided into two groups based on their participation in the Kahoot quiz. Since the Kahoot quizzes were held in every class, the number of students in each group were varied on a weekly basis.

The data from the Kahoot quizzes and from the exams was merged into a table (see Table 1). For each question, three columns were created to mark the results. The first column showed if the student answered correctly (1) or not (0) during the Kahoot quiz in the class. This does not mark whether the student had participated in the quiz or not; that was calculated from the Kahoot reports.

The data in the other two columns was based on the results of the exam. The middle column indicated if the student correctly marked the same answer as in the Kahoot quiz. The column on the right marked the number of incorrect answers that the student marked in the exam. The impact of the Kahoot quiz on the learning experience was based on the overall results of the Kahoot, the exam and the number of mistakes.

Table 1 Data input structure

\begin{tabular}{lccc}
\hline \multirow{2}{*}{$\begin{array}{l}\text { Student } \\
\text { ID }\end{array}$} & Kahoot result & Exam result & $\begin{array}{c}\text { Number of } \\
\text { mistakes }\end{array}$ \\
\cline { 2 - 4 } & $1-$ if correct & $1-$ if correct & [number of wrong \\
Student 1 & $0-$ if not correct & $0-$ if not correct & answers] \\
\hline
\end{tabular}




\section{Results}

The students $(\mathrm{N}=200)$ were categorized according to how many Kahoot quizzes they participated in (see Table 2). Based on this, the $8+1$ group was created. The students that did not take part in any of the eight Kahoot quizzes became the control group ( $n=75)$, marked in the data as 0 .

The overall result shows (see Fig. 1) a trend; those students who participated in more Kahoots (took part in class) did better on the full exam. The result cannot be fully attributed to Kahoot, as it could be that those students were more hardworking.

In Fig. 2, the multiple-choice questions and the True or False questions can be viewed separately. Interestingly, participating in more Kahoot quizzes only showed a positive effect in the multiple-choice questions. With the True or False questions, progress was not detected.

Fig. 3 shows the percentage of correct answers, comparing the students that did not play Kahoot with those that played. Here, the results are combined from the students that attended one to eight Kahoots. In Fig. 3, students that took part in any Kahoot quiz marked the correct answer in a higher percentage. Furthermore, they made significantly less errors.

\section{Conclusion}

In this study, the effectiveness of weekly Kahoot quizzes was measured in a high-stakes tests.

Based on the gathered data, it is clear that the students that participated in Kahoot quizzes reached a better overall result. This could be for several reasons. For instance, the students who participated in more Kahoot quizzes are more diligent students. Secondly, for them it was easier to recall the information because they had seen it before.

Furthermore, the students who participated in the Kahoot quizzes tended to mark less incorrect answers in the exam, even if they did not answer correctly during the Kahoot quiz in class.

In the True or False questions, the difference between the two groups was not significant. This shows that the Kahoot quiz is more useful for students in the multiple-choice setup.

Moreover, even if in the Kahoot quiz the student did not mark the correct answer, they had a higher rate of recalling the correct answer during the exam.

In conclusion, a Kahoot quiz done weekly at the end of each class tended to help students recall and choose the correct answers for the questions in the exam. Therefore, participating in Kahoot quizzes raised the efficiency of the students' learning process.
Table 2 Categories based on the number of Kahoots the students participated

\begin{tabular}{lccccccccc}
\hline $\begin{array}{l}\text { SUM nr. Kahoot } \\
\text { attendance }\end{array}$ & 0 & 1 & 2 & 3 & 4 & 5 & 6 & 7 & 8 \\
\hline $\begin{array}{l}\text { Number of students } \\
\text { in group }\end{array}$ & 75 & 19 & 12 & 17 & 18 & 14 & 16 & 12 & 17 \\
\hline
\end{tabular}

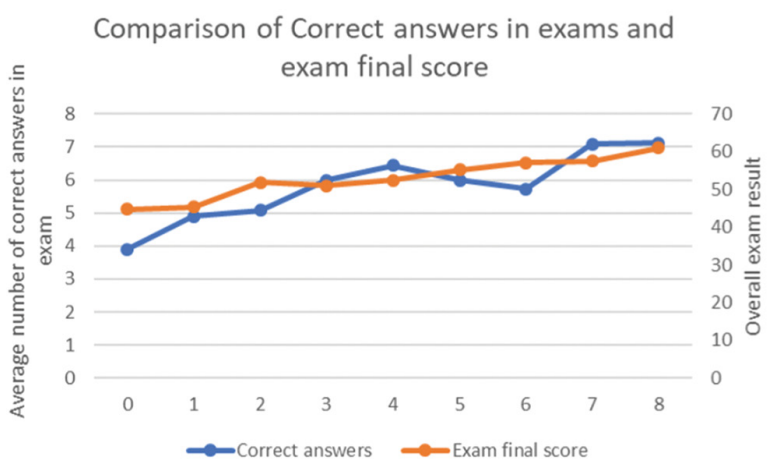

Fig. 1 Number of Kahoot participation divided between the correct answers and exam scores

Average correct answers in exam

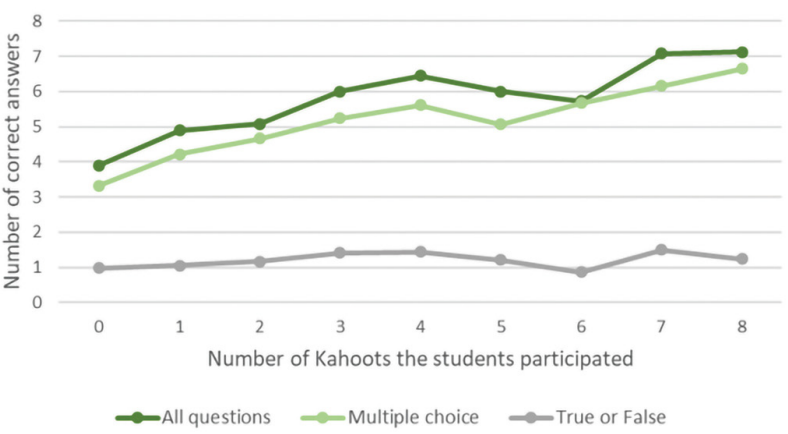

Fig. 2 Average correct answers marked in the exam categorized based on the total number of Kahoots the student participated

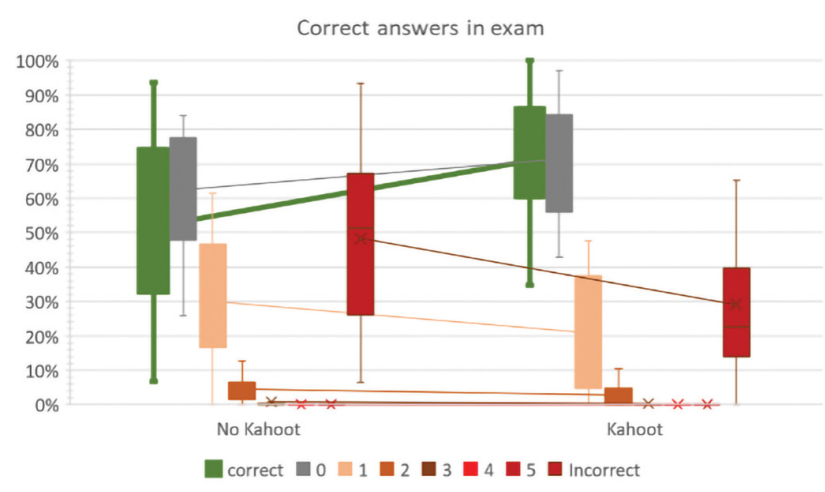

Fig. 3 Average correct answers in the exam based on the participation in Kahoot

\section{Discussion}

More detailed research needs to be done with more parameters to measure. For this, a digital exam could be a solution, such as an online test on the Moodle platform. 
Moreover, to understand the students' learning styles and influential factors based on the theories presented in Section 2.2, a more interactive and regular task and challenge system needs to be implemented during the

\section{References}

Andrzej, M. (2015) "Even Ninja Monkeys Like to Play: Gamification, Game Thinking and Motivational Design", CreateSpace Independent Publishing. [online] Available at: https://www.gamified.uk/evenninja-monkeys-like-to-play/ [Accessed: 10 August 2017]

Barata, G., Gama, S., Jorge, J., Gonçalves, D. (2014) "Identifying Student Types in a Gamified Learning Experience", International Journal of Game-Based Learning, 4(4), pp. 19-36. https://doi.org/10.4018/ijgbl.2014100102

Barata, G., Gama, S., Jorge, J., Gonçalves, D. (2015) "Gamification for smarter learning: tales from the trenches", Smart Learning Environments, 2(1), 10. https://doi.org/10.1186/s40561-015-0017-8

Bartle, R. (1996) "Hearts , Clubs, Diamonds, Spades : Players Who Suit MUDs", [online] Available at: http://www.mud.co.uk/richard/ hcds.htm [Accessed: 11 February 2018]

Bernik, A., Radošević, D., Bubaš, G. (2017) "Introducing gamification into e-learning university courses", In: 2017 40th International Convention on Information and Communication Technology, Electronics and Microelectronics, MIPRO, Opatija, Croatia, 2017, pp. 711-716.

https://doi.org/10.23919/MIPRO.2017.7973515

Bicen, H., Kocakoyun, S. (2018) "Perceptions of Students for Gamification Approach: Kahoot as a Case Study", International Journal of Emerging Technologies in Learning, 13(2), pp. 72-93. https://doi.org/10.3991/ijet.v13i02.7467

Bishop, J. (2014) "Gamification for Human Factors Integration: Social, Education, and Psychological Issues", Gamification for Human Factors Integration: Social, Education, and Psychological Issues, 1st ed., IGI Global, Hershey, PA, USA. https://doi.org/10.4018/978-1-4666-5071-8

Bista, S. K., Nepal, S., Colineau, N., Paris, C. (2012) "Using gamification in an online community", In: 8th International Conference on Collaborative Computing: Networking, Applications and Worksharing (CollaborateCom), Pittsburgh, PA, USA, 2012, pp. 611-618.

Challco, G. C., Mizoguchi, R., Bittencourt, I. I., Isotani, S. (2015) "Steps Towards the Gamification of Collaborative Learning Scenarios Supported by Ontologies", In: Conati C., Heffernan N., Mitrovic A., Verdejo M. (eds) Artificial Intelligence in Education. AIED 2015. Lecture Notes in Computer Science, Vol. 9112, Springer, Cham, Switzerland. https://doi.org/10.1007/978-3-319-19773-9_60

Chapman, J., Rich, P. (2017) "Identifying Motivational Styles in Educational Gamification", In: Proceedings of the 50th Hawaii International Conference on System Sciences, Hilton Waikoloa Village, Hawaii, USA, pp. 1318-1327. https://doi.org/10.24251/HICSS.2017.157 semester. This way, more data can be gathered, more categories could be created based on student types and the most suitable learning method could be chosen.

Chen, C.-M., Lin, S.-T. (2014) "Assessing effects of information architecture of digital libraries on supporting E-learning: A case study on the Digital Library of Nature \& Culture", Computers \& Education, 75, pp. 92-102. https://doi.org/10.1016/j.compedu.2014.02.006

Chou, Y.-K. (2015) "Actionable Gamification - Beyond Points, Badges, and Leaderboards. Octalysis Media", CreateSpace Independent Publishing Platform, USA.

Conole, G., Klobučar, T., Rensing, C., Konert, J., Lavoué, É. (2015) "Design for Teaching and Learning in a Networked World: 10th European Conference on Technology Enhanced Learning, EC-TEL 2015, Toledo, Spain, September 15-18, 2015, Proceedings", Springer, Cham, Switzerland. https://doi.org/10.1007/978-3-319-24258-3

Dečman, M. (2015) "Modeling the acceptance of e-learning in mandatory environments of higher education: The influence of previous education and gender", Computers in Human Behavior, 49, pp. 272-281. https://doi.org/10.1016/j.chb.2015.03.022

Deterding, S., Dixon, D., Khaled, R., Nacke, L. (2011) "From game design elements to gamefulness: defining "gamification"', In: MindTrek'11 Proceedings of the 15th International Academic MindTrek Conference: Envisioning Future Media Environments, Tampere, Finland, pp. 9-15. https://doi.org/10.1145/2181037.2181040

Diamond, L., Tondello, G. F., Marczewski, A., Nacke, L. E., Tscheligi, M. (2015) "The HEXAD Gamification User Types Questionnaire : Background and Development Process", In: Workshop on Personalization in Serious and Persuasive Games and Gamified Interactions, London, UK.

Eyal, N., Hoover, R. (2014) "Hooked: How to Build Habit-Forming Products", 1st ed., Portfolio, city of publication?, USA.

Ferro, L. S., Walz, S. P., Greuter, S. (2013) "Towards personalised, gamified systems: an investigation into game design, personality and player typologies", In: IE '13 Proceedings of The 9th Australasian Conference on Interactive Entertainment: Matters of Life and Death, Melbourne, Australia, Article No. 7. https://doi.org/10.1145/2513002.2513024

Fogg, B. J. (2009) "A behavior model for persuasive design", In: Persuasive '09 Proceedings of the 4th International Conference on Persuasive Technology, Claremont, California, USA, Article No. 40. https://doi.org/10.1145/1541948.1541999

González, C. S., Toledo, P., Muñoz, V. (2016) "Enhancing the engagement of intelligent tutorial systems through personalization of gamification", International Journal of Engineering Education, 32(1), pp. 532-541. 
Hamari, J. (2017) "Do badges increase user activity? A field experiment on the effects of gamification", Computers in Human Behavior, 71, pp. $469-478$.

https://doi.org/10.1016/j.chb.2015.03.036

Hamari, J., Koivisto, J., Sarsa, H. (2014) "Does Gamification Work? -A Literature Review of Empirical Studies on Gamification", In: 2014 47th Hawaii International Conference on System Sciences, Waikoloa, HI, USA, pp. 3025-3034.

https://doi.org/10.1109/HICSS.2014.377

Hercegfi, K. (2011) "Event-Related Assessment of Hypermedia-Based E-Learning Materials With an HRVBased Method That Considers Individual Differences in Users", International Journal of Occupational Safety and Ergonomics, 17(2), pp. 119-127. https://doi.org/10.1080/10803548.2011.11076882

Honey, P., Mumford, A. (1982) "The Manual of Learning Styles", $3^{\text {rd }}$ ed., Peter Honey, Maidenhead, UK.

Hunicke, R., LeBlanc, M., Zubek, R. (2004) "MDA: A Formal Approach to Game Design and Game Research", In: Workshop on Challenges in Game Artificial Intelligence, San Jose, California, pp. 1-4.

Iwamoto, D. H., Hargis, J., Taitano, E. J., Vuong, K. (2017) "Analyzing the Efficacy of the Testing Effect Using Kahoot ${ }^{\mathrm{TM}}$ on Student Performance", Turkish Online Journal of Distance Education, 18(2), pp. 80-93. https://doi.org/10.17718/tojde.306561

Kocadere, S. A., Çağlar, Ş. (2018) "Gamification from Player Type Perspective : A Case Study", Journal of Educational Technology \& Society, 21(3), pp. 12-22. [online] Available at: https://www.jstor. org/stable/26458503[Accessed: 10 April 2018]

Lewis, C. (2014) "Irresistible Apps: Motivational Design Patterns for Apps, Games, and Web-based Communities", Apress, Berkeley, CA, USA.

https://doi.org/10.1007/978-1-4302-6422-4

Lindberg, R. S. N., Laine, T. H. (2017) "Approaches to Detecting and Utilizing Play and Learning Styles in Adaptive Educational Games", In: Costagliola, G., Uhomoibhi, J., Zvacek, S., McLaren, B. (eds) Computers Supported Education. CSEDU 2016. Communications in Computer and Information Science, Vol. 739, Springer, Cham. https://doi.org/10.1007/978-3-319-63184-4_18

Liu, A., Li, T. M. (2016) "Develop Habit-forming Products Based on the Axiomatic Design Theory", Procedia CIRP, 53, pp. 119-124. https://doi.org/10.1016/j.procir.2016.07.035

Machado, M., Tao, E. (2007) "Blackboard vs. Moodle: Comparing User Experience of Learning Management Systems", In: 2007 37th Annual Frontiers In Education Conference - Global Engineering: Knowledge Without Borders, Opportunities Without Passports, Milwaukee, WI, USA, pp. S4J-7-S4J-12. https://doi.org/10.1109/FIE.2007.4417910

Magoulas, G. D., Papanikolaou, Y., Grigoriadou, M. (2003) "Adaptive web-based learning: accommodating individual differences through system's adaptation", British Journal of Educational Technology, 34(4), pp. 511-527. https://doi.org/10.1111/1467-8535.00347

Nicholson, S. (2012) "A User-Centered Theoretical Framework for Meaningful Gamification", presented at Games+Learning+Society, Madison, WI, USA.

Oliver, E. (2017) "Gamification as transformative assessment in higher education", HTS Teologiese Studies/Theological Studies, 73(3), a4527. https://doi.org/10.4102/hts.v73i3.4527
Palmer, D., Lunceford, S., Patton, A. J. (2012) "The engagement economy: How gamification is reshaping businesses", Deloitte Review, (11), pp. 52-69. Available at: http://dupress.com/articles/the-engagement-economy-how-gamification-is-reshaping-businesses/ [Accessed: 12 February 2014]

Rapp, A. (2014) "A SWOT Analysis of the Gamification Practices: Challenges, Open Issues and Future Perspectives", In: 5th International Conference on Applied Human Factors and Ergonomics AHFE 2014, Kraków, Poland, pp. 6919-6930.

Reiners, T., Wood, L. C. (2015) "Gamification in Education and Business", Springer, Cham. https://doi.org/10.1007/978-3-319-10208-5

Ryan, R. M., Deci, E. L. (2000) "Self-determination theory and the facilitation of intrinsic motivation, social development, and well-being", American Psychologist, 55(1), pp. 68-78. https://doi.org/10.1037/0003-066X.55.1.68

Sailer, M., Hense, J., Mandl, H., Klevers, M. (2013) "Psychological Perspectives on Motivation through Gamification", Interaction Design and Architecture(s) Journal, (19), pp. 28-37.

Seaborn, K., Fels, D. I. (2015) "Gamification in theory and action: A survey", International Journal of Human-Computer Studies, 74, pp. 14-31. https://doi.org/10.1016/j.ijhcs.2014.09.006

Sharek, D., Wiebe, E. (2014) "Measuring Video Game Engagement Through the Cognitive and Affective Dimensions", Simulation \& Gaming, 45(4-5), pp. 569-592. https://doi.org/10.1177/1046878114554176

Simões, J., Redondo, R. D., Vilas, A. F. (2013) "A social gamification framework for a K-6 learning platform", Computers in Human Behavior, 29(2), pp. 345-353. https://doi.org/10.1016/j.chb.2012.06.007

Solmaz, E., Cetin, E. (2017) "Ask-Response-Play-Learn: Students' views on gamification based interactive response systems", Journal of Educational and Instructional Studies in the World, 7(3), pp. $28-40$.

Tan, D., Ganapathy, M., Kaur, M. (2018) "Kahoot! It : Gamification in Higher Education Kahoot! It : Gamification in Higher Education", Pertanika Journal of Social Science and Humanities, 26(1), pp. 565-582.

Taylor, J. C. (2000) "Teaching and Learning Online : The Workers, The Lurkers and The Shirkers", University of Southern Queensland,

Toth, A., Logo, E. (2017) "The Possibilities of Creating an Experience Based University Course on an Online Platform with the Tools of Gamification", In: 4th International Conference SGEM 2017 Social Sciences \& Arts, Albena, Bulgaria, pp. 581-588.

Tóth, Á., Tóvölgyi, S. (2017) "The Introduction of Gamification: A review paper about the applied gamification in the smartphone applications", In: 2016 7th IEEE International Conference on Cognitive Infocommunications (CogInfoCom), Wroclaw, Poland, pp. 000213-000218. https://doi.org/10.1109/CogInfoCom.2016.7804551

Wang, A. I., Zhu, M., Saetre, R. (2016) "The Effect of Digitizing and Gamifying Quizzing in Classrooms", In: 10th European Conference on Games Based Learning, Paisley, UK, pp. 729737. [online] Available at: https://brage.bibsys.no/xmlui/handle/11250/2426374 [Accessed: 21 March 2018] 